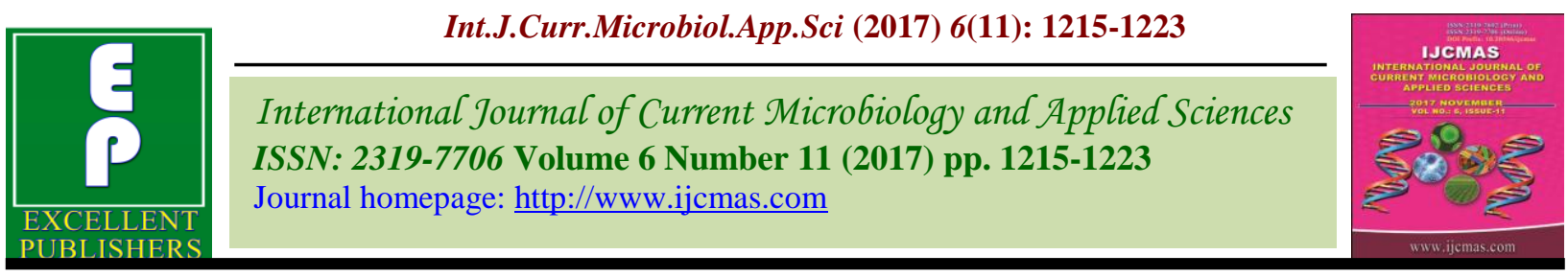

Review Article

https://doi.org/10.20546/ijcmas.2017.611.144

\title{
Pharmacological Profile of Asparagus racemosus: A Review
}

\author{
Pooja Shaha and Anurag Bellankimath* \\ Department of Biotechnology, Basaveshwar Engineering College, \\ Bagalkot- 587102, Karnataka, India \\ *Corresponding author
}

\section{A B S T R A C T}

\begin{tabular}{|l|}
\hline Ke y w o r d s \\
$\begin{array}{l}\text { Shatavari, Medicinal } \\
\text { plant, Morphology, } \\
\text { Pharmacological } \\
\text { profile. }\end{array}$ \\
\hline Article Info \\
\hline $\begin{array}{l}\text { Accepted: } \\
\text { 12 September } 2017 \\
\text { Available Online: } \\
\text { 10 November } 2017\end{array}$ \\
\hline
\end{tabular}

Keywords

Shatavari, Medicinal Pharmacological profile.

\section{Introduction}

Asparagus racemosus is an important medicinal plant of tropical and subtropical India. Its medicinal use has been accounted in the Indian and British Pharmacopoeias and in indigenous systems of medicine. The genus Asparagus racemosus includes about 300 species around the globe. The genus is thought to be medically important because of the presence of steroid saponins and sapogenins in various parts of the plant. Out of the 22 species of Asparagus recorded in India; Asparagus racemosus is the single most commonly used in traditional medicine. Use of Asparagus racemosus was mentioned in the ancient literature of Ayurveda. It is used to rectify the gynecological problems like irregularities in menstrual cycle and sexual dysfunction. Even till today the containing Asparagus racemosus are used to adjust the menstrual irregularities by Ayurvedic practitioner many formulations containing Asparagus racemosus are presently available in the marketplace for work. Therapeutic usage of the Asparagus is due to the phytoestrogenic components present in it.

\section{Nomenclature}

The plant Asparagus racemosus can be classified as given in the table 1.

\section{Morphology}

Shatavari is a highly branched, consisting of thorn under shrubs. It is a woody climber 
plant which is $1-2 \mathrm{~m}$ in distance and readily grows up a documentation or over other plant. The leaves of the Shatavarilooks like pine needles, uniform and small in size. The roots of the plant have a finger like structure and are clustered in nature. It has a tiny white coloured flower while the plant itself is bittersweet in taste (Amit Chawla et al., 2011) (Fig. 1).

\section{Habitat}

Racemosus shrubs contain succulent roots and rows at an altitude of $1500 \mathrm{~m}$ above the sea level. It is spread throughout the tropical Africa, Java, Australia, India and southern section of the china (Jayashree et al., 2013).

\section{Microscopy of Asparagus racemosus}

\section{Powdered microscopy}

\section{Root}

Root is one of the main part of Asparagus racemosus which is used in the pharmacological studies. The root tuber in its powdered state is morphologically pale yellow in colour, odourless and slight sweetish in taste. The powder mainly consists of the parenchyma cells with or without the inter-cellular spaces. While more or less amount of starch grains presented in the powder, it largely consisted of the acicular rapids, rapid bundles and pericyclic fibres (Fig. 2).

The different extracts can be obtained from the employment of different solvents with the efficiency ranging from $41.25 \%$ for alcohol extracts and $0.6 \%$ from that of petroleum ether extracts (Mahesh Kawale et al., 2014).

\section{Anatomical structure}

The Microscopic outline of the T.S section of the plant composed of the periferous cell layers which are composed of small thin cell walls and are elongated to form the root cortex. The hair cortex can be split into two regions, namely outer cortex and inner cortex. These layers are 25-29 in number and can be present either in group or as a single entity forming the continuous to discontinuous regions in the outer regions (Nagar B. P et al., 2011). The epidermal cells are much elongated with the longitudinal orientation to axis if the organ. They likewise bear a smooth surface, rapids are also present. The vascular bundle pattern is dispersed in nature with great amount of xylem vessels. These are paired and circular in nature and outline with large lumen. The flora delivers a total of twelve of these vascular bundles (Rupali Subhashrao Kaikade et al., 2015).

\section{Chemical constituents}

Primary metabolites can be specified as the components which are immediately involved in normal growth and evolution, while secondary metabolites are the organic compounds that are not immediately required in the plant growth. The major bioactive components present in the plant are steroidal saponins. It mainly contains six components, Shatavarin I-VI, with shatavarin IV a major glycoside being present in the roots of the plants. The structure of shatavarin IV consist of two molecules of asparagus rhamnose along with 1 molecule of glucose and is mainly found in the leaf, fruits and roots of the plant (Amit Chawla et al., 2011).

The trace elements like copper, zinc, manganese, cobalt, potassium, calcium and selenium can also be found (Mohanta et al., 2003), fruits and flowers of shatavari contains flavanoids which are nothing but glycosides of quercetin, rutin and hyperosides (Kamat et al., 2000).

Kaepfrol is another component along with that of sarsapogenium which can be isolated 
from the woody portions of the tuberous roots (Choudhary et al., 1992). Some of the essential fatty acids like gamma linoleinic acids, disogenin are also obtained from this plant. (Shashi Alok et al., 2013).

\section{Pharmacological profile}

\section{Gastrointestinal effects}

The powdered dried roots of Asparagus racemosus promote gastric emptying in healthy volunteers and its action comparable with that of the synthetic dopamine antagonist metoclopramide (Dalvi et al., 1990).It has been reported that $A$. racemosus along with Terminalia chebulaprotect gastric mucosa against pentagastrin and carbachol induced ulcers, by significantly reducing both severity of ulceration and ulcer index (Dahanukar et al., 1983).

Shatavari is primarily known to ease the pain and burning sensation as well as other dyspeptic symptoms due to the ulcers. Since it does not have any antacids or anti-secretory properties, the observed mild acid secretion can be ascribable to the changes in gastric mucosa (Singh et al., 1983).

\section{Galactagogue effect}

Alcoholic extract of Asparagus racemosus have a significant effect on lactating mother to increase milk production and have been observed along with increased growth of the mammary gland alveolar tissue and acini. The growth of lobuloavelar tissue and milk secretion in the estrogenic primed rats was thought to be due to the action of released corticoids or prolactin (Amit Chawla et al., 2011) (Fig. 3). The galactagogue effect has also been studied in buffalo as described by Patel et al., (Patel et al., 1969). As described by Akansha Singh et al., the effect was evaluated in 60 lactating mothers by measuring the change in the prolactin hormone level. The study shows that the oral administration of A. racemosus led to thrice increase the level of prolactin than that of the control group.

\section{Immunomodulatory activities}

The use of Asparagus racemosus dried root powder modulates the action of the immune system. That in turn, decreases the inflammatory response. It induces the immune system to fight against immune deficiencies (like AIDS), infections and cancer. It may be helpful in obtaining higher protective antibody against different vaccinations including more effective cell mediated immune response for protection against various bacterial, viral, and other diseases. Several workers has studied the effect of Asparagus racemosus root extract in augmentation of humoral and cell mediated immune response providing better protection level against infections (Akansha Singh et al., 2014).

\section{Anticancer activity}

Natural products have long been used for treatment against cancer. There are at least 10000 species of plants, documented to have anti-cancerous properties. As described by Shankar et.al the isolated shatavarin IV along with AR-2B containing 5.05\% shatavarin IV showed potent cytotoxicity. It showed increase in non-viable cell count when compared to untreated mice of group in the study (Chitme et al., 2009). Hence from various in vitro and in vivo models it can be concluded that the root extract of the plant which contains shatavari IV fraction exhibits significant activity against cancer cells.

\section{Cardiovascular effects}

Increase in serum lipid levels especially cholesterol along with the generation of reactive oxygen species are the major reasons 
for development of coronary artery disease and atherosclerosis 'Abana' a herbo-mineral formulation containing $10 \mathrm{mg}$ Asparagus racemosus extract per tablet, as found to have significant hypocholerolacemic effect in rats and therefore established a potential for use as a cardio-protective agent.

The Asparagus racemosus root powder supplements decreased lipid peroxidation and causes a dose-dependent reduction in lipid profiles. The total lipids, total lipids, total cholesterol and triglycerides in plasma and liver as well as plasma LDL (low density lipoprotein) and VLDL (very low density lipoprotein) cholesterol decrease. Through it can be hypothesized that the hypocholesteremia is alleviated by decreasing and increasing conversion of endogenous cholesterol to bile acid (Shankar K. Mitra et al., 2012).

\section{Immunological activity}

The use of Asparagus racemosus dried root powder modulates the activity of immune system. That in turn, decreases the inflammatory response. It induces the immune system to fight against immune deficiencies (like AIDS), infections and cancer.

It may be helpful in obtaining higher protective antibody against different vaccinations including more effective cell mediated immune response for protection against various bacterial, viral, and other diseases. Several workers has studied the effect of Asparagus racemosus root extract in augmentation of humoral and cell mediated immune response providing better protection level against infections (Khanna et al., 1991).

\section{Antidiabetic effect}

Diabetes mellitus (DM) is a major reason of disability and hospitalization that parents a substantial burden on companies worldwide. In such circumstances, herbal medicines for the treatment of diabetes become significant. Asparagus racemosus roots have been reported to reduce blood glucose level in rats, and rabbits. Asparagus racemosus root extract causes a wide ranging stimulatory effect on physiological insulinotropic pathways (Fuller et al., 1983).

\section{Antioxidant action}

Antioxidants are the moieties which are involved in the prevention of cell damage, common pathway for many diseases. As given by Aarati $\mathrm{K}$ the Methanolic extract of the root possess significant anti-oxidant properties when administered through the oral method.

The levels of enzymes like superoxidase dismutase, catalase and ascorbic acid increase with significant reduction in the lipid peroxidation. The antioxidant properties were mainly exhibited due to the presence of Isoflavons (Wiboonpun et al., 2004).

\section{Antiulcer effect}

Ulcer is one of the burning problems in developing and even developed countries. It is induced due to imbalance among aggressive factors, especially gastric acid and pepsin, and protecting factors including gastric mucosa, bicarbonate and prostaglandin.

Asparagus racemosus is an effective antiulcerogeneric agent whose activity can easily be compared with that of ranitidine hydrochloride Asparagus racemosus causes an inhibitory effect on release of gastric hydrochloric acid, and protects gastric mucosal damage. Hence the roots of the Shatavari plant in the form of powder can be administered to chronic ulcer patients along with other patients (Anil Mangal et al., 2004). 


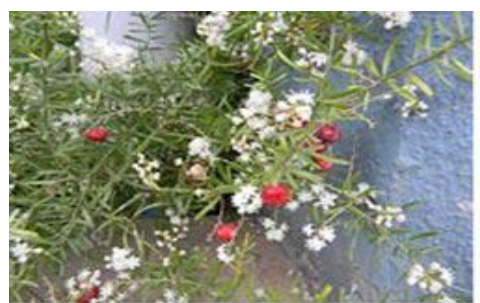

Fig.1a Shatavari plant

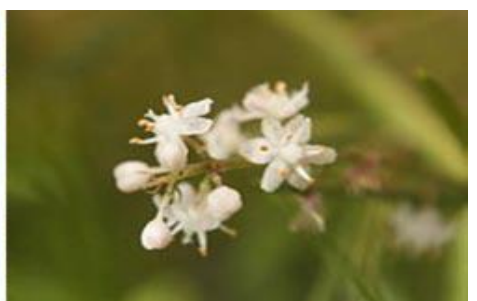

Fig.1b Closeup on flowers

Fig.2 Powdered form of root, A - Vascular Elements, B - Tracheids fragments, C - Acicular Raphides and Raphide Bundles, D - Vessel elements, E - Starch grains

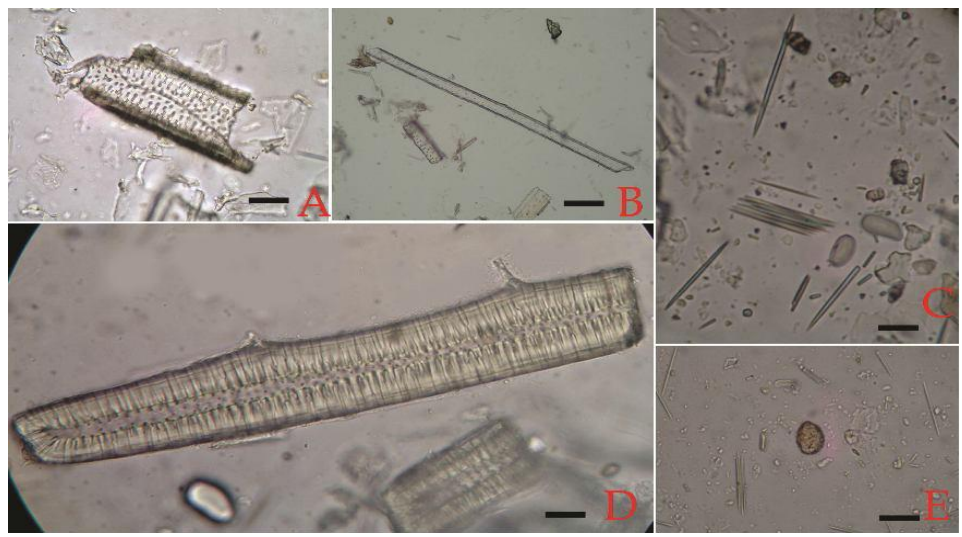

Fig.3 1 - Asparagus racemosus gonoclados habit, 2 - Fresh drug (root tubers), 3 - T.S of root tuber, 4 - Portion showing exodermis and cortex, 5 - portion showing stellar region, 6 - Stele enlarged, $7 \& 8$ - Portion showing cortex, raphide bundle and sap cell content, 9 to 23 - Macerate, 9 - Portion showing piliferous layer with root hairs, 10 - Unicellular root hair, 11 to14 Parenchyma cells, 15 to 17 - Pitted parenchyma, 18- Aseptate fibre, 19- Septate fiber,20 Tracheid, 21 to 23 - Vessels

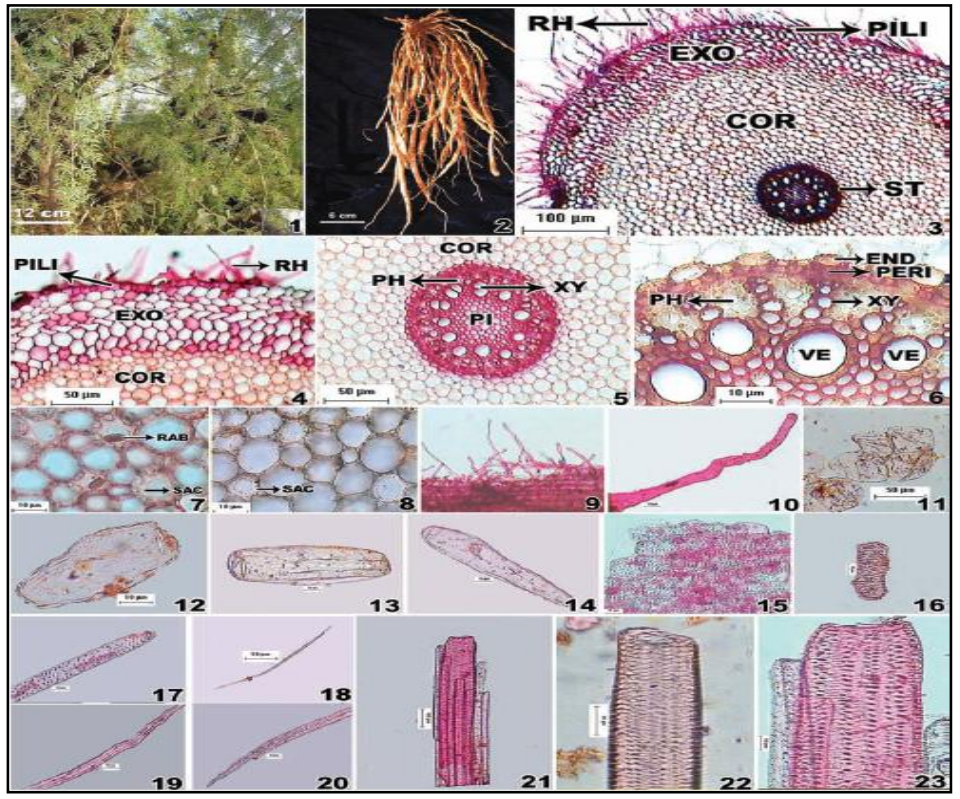




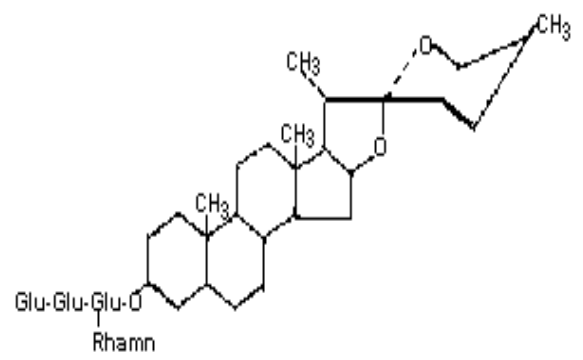

Fig.4 Satavarin I

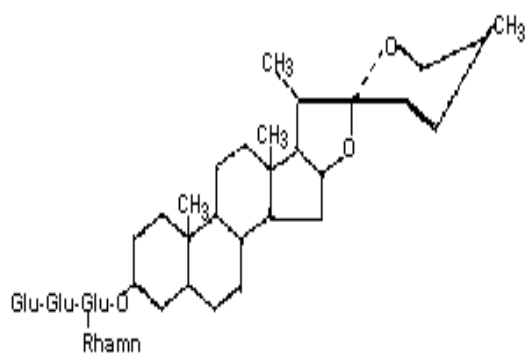

Fig.5 Sarasasapogenin

Table.1 Nomenclature of Asparagus racemosus

\begin{tabular}{|c|c|}
\hline Kingdom & Plantae \\
\hline Clade & Angiosperms \\
\hline Clade & Monocots \\
\hline Order & Asparagales \\
\hline Family & Asparagaceae \\
\hline Sub family & Asparagoidea \\
\hline Genus & Asparagus \\
\hline Species & Aracemos \\
\hline
\end{tabular}

\section{Antidiarrhoeal effect}

Diarrhoea can be classified as one of the major problems faced mainly in the developing countries with an estimated death rate of 2.2 million people globally, mainly in the developing countries. The fatal cases can be mainly seen in the children with the 5 years of age (Nishritha Bopana et al., 2007). The ethanol and aqueous extracts of roots of A. racemosus exhibited a significant antidiarrhoeal activity against the castor oil induced diarrhoea in the rats as described by the Venkatesan et al., (2005). Studies have shown that the action of "prostaglandin E" caused the diarrhoea in the test subjects, hence it can be said that the action of this can be to prevent the biosynthesis of prostaglandin which in turn inhibits the diarrhoeal effect.

\section{Antitussive effect}

A. racemosus has been commonly used in the treatment of cough and in minor upper respiratory tract infection, exhibiting the antitussive properties. In the experimental setup by Akansha Singh and Sinha (2014) the methanol extract of the roots showed activity against sulphur induced cough in mice which was likened to the codeine phosphate, a drug obtained from opium.

Hence this extract can be used against the opium based drugs, since there are no side effects like nausea, sweating, tiredness which can be observed by use of codeine phosphate associated drugs.

\section{Aphrodisiac activity}

Lyophilized aqueous extracts roots of Asparagus racemosus have sexual behavioral effect in male albino rats. Administration of the aqueous extracts has pronounced anabolic effect in treated animals as evidenced by weight gains in body and reproductive organs. There was a significant variation in the sexual behaviour of animals as reflected by reduction of mount latency ejaculation latency, post 
ejaculatory latency, intromission latency (Mayank Thakur et al., 2004).

\section{Anti-dyspepsia effect}

Dyspepsia is the condition characterised by the inability to digest, commonly stated as impaired digestion which is frequently associated with the gastritis. In small minority it can as well be the first symptom for gastric ulcer and cancer. As recorded by David S S, et.al the activity was analysed in the healthy human volunteers. The Shatavari was compared with that of Metoclopramide, which is a synthetic dopamine used in patients with dyspepsia to increase the rate of emptying of the abdomen. Hence it was found that the rate of emptying did not differ significantly. It can be reasoned that the extract can be utilised for the treatment and the side effects from the use of metoclopramide like drowsiness can be averted (Dalvi et al., 1990).

\section{Problems associated with menstruation}

The constituents of Asparagus racemosus make it useful in menstrual disorders such as dysmenorrhea, premenstrual syndrome, irregular bleeding during peri-menopausal period and also in situations after menopause. Asparagus racemosus contain saponins which hinder the oxytocic activity on uterine musculature, thereby maintain the spontaneous uterine motility, confirming its utility in dysmenorrhea which comprises of painful menstruation without significant pelvic pathology.

\section{Problems associated with menopause}

A common practice to relieve menopausal symptoms is to administer hormone replacement therapy, which is not free from adverse effect. Thus women are turning to natural medication in an effort to deliver a dependable alternative to synthetic steroidal hormones. Asparagus racemosus being known sources of phytoestrogen can be effective in reducing adverse menopausal symptoms (The chemical entities from plants which mimic hormone are called phytoestrogens). These are weaker than natural estrogen in action (Aarti, 2015).

Various studies have been conducted on $A$. racemosus. Shatavari is a very important medicinal plant, which can be applied in different phases of medicament which is demonstrated by its function in the traditional practices as well as several modern works. Several experiments have been taken away to explore the pharmacological activities and the potential applications of the plant in the pharmaceutical industries are countless. Hence, further detailed and systematic study must be taken out, which can provide better knowledge and understanding the pharmacological importance of this plant.

\section{References}

Aarti. K, 2015, "Asparagus racemosus (shatavari): a multipurpose plant", European journal of Pharmaceutical and medical research, Page No 599-613.

Akansha Singh, B Sinha, 2014, Pharmacological significance of Satavari: Queen o fherbs, "International Journal of Phytomedicine", Issue 6, Page No: 477-488

Amit Chawla, Payal Chawla, Mangalesh, R C Roy, 2011, "Asparagus racemosus (Wild): Biological Activities \& its Active Principles" Indo-Global Journal of Pharmaceutical Sciences, Vol 1, Issue 2: Page No. 113-120

Anil Mangal, Debashis Panda, M C Sharma, 2004, "Peptic ulcer healing properties of Shatavari (Asparagus racemosus Willd)", International Journal of Traditional Knowledge, Vol 5, Issue 2, 
Page No - 227-228.

Chitme, H.R., I.S. Muchandi, S.C. Burli, 2009, "Effect of Asparagus racemosus Willd root extract on Ovariectomized rats", The Open Natural Products journal, Vol 2, Page No- 16-23.

Choudhary B K and Kar A, "Mineral Contents of Asparagus racemosus", Indian Drugs, (1992), Volume 29, Page No: 623-628

Dahanukar, S.A., S. G. Date, S. M. Karandikar, 1983, "Cytoprotective effect of Terminalia chebula and Asparagus racemosus on gastric mucosa". Indian Drugs, Issue: 21, Page No- 442-445.

Dalvi S S, Nadkarni P M, Gupta K C, 1990, "Effect of Asparagus racemosus (Shatavari) on gastric emptying time in normal healthy volunteers", Journal of Postgrad. Med. Vol 36, Page No -91.

Dalvi, S.S., P M Nadkarni, K C Gupta, 1990, "Effect of Asparagus racemosus (Shatavari) on gastric emptying time in normal healthy Volunteers", Journal of Postgraduate Medicine, Volume: 36, Issue: 2, Page: 91-4

Fuller J H, Elford J, Goldblatt P, Adelstein.A. M, 1983, "Diabetes mortality: new light on an underestimated public health problem", Diabetologia, Vol 24, Page No-336 -341.

Jayashree G. V, Rachitha.P, Krupashree K, Hemanthkumar. K and Farhathkhanum, 2013, "Phytochemical analysis of methanolic extract of roots of Asparagus racemosus (Shatavari)", International Journal of Pharma and Bio Sciences, Vol 4, Issue 4: Page No. 250254.

Kamat J P, Boloor K K, Devasagayam T P and Venkatachalam S R., 2000, "Antioxidant Properties of Asparagus racemosus against Damage Induced By Gamma-Radiation In Rat Liver Mitochondria", J. Ethnopharmacol,
Volume 71, Page No: 425-435

Khanna A.K., Chander, R, Kapoor, N.K, 1991, "Hypolipidaemic Activity of Abana in Rats", Fitoterapia, Vol 63, Issue 3, Page No - 271

Mahesh Kawale, SandipAnkoliya, R. Saravanan, Tushar Dhanani and $\mathrm{P}$ Manivel, 2014, "Pharmacognostical and physicochemical analysis of Asparagus adscendens Buch. Ham. exRoxb. (Shweta musali)", Journal of Pharmacognosy and Phytochemistry, Vol 3, Issue 4: Page No. 131-139.

Mayank Thakur, Nagendra S. Chauhan, Shilpi Bhargava, Vinod K. Dixit,2009, "A Comparative Study on Aphrodisiac Activity of Some Ayurvedic Herbs in Male Albino Rats", Arch Sex Behav, Vol 38, Page No - 1009-1015.

Mohanta, B., A. Chakraborty, M. Sudarshan, R. K. Dutta, M. Baruah, 2003, Elemental profile in some common medicinal plants of India Its correlation with traditional therapeutic usage, Vol. 258, No. 1, Page No:175-179.

Nagar B. P, Duttgarg V, Dhiman A, 2011, "Ethnopharmacology, phytochemistry and Bioactivity of Asparagus racemosus: an update", Pharmacologyonline 2: 979-994.

NishrithaBopana, Sanjay Saxena, 2007, "Asparagus racemosusEthnopharmacological evaluation and conservation needs", Journal of Ethnopharmacology, Vol 110, Page No- 1-15.

Patel, A.B., U. K. Kanitkar, 1969, “Asparagus racemosus wild form bordi, as a galactogogue in buffaloes", Indian Veterinary Journal, Volume - 46, Page No- 718-721.

Rupali Subhashrao Kaikade and Shubhangi Nagorao Ingole, 2015, "Study of Anatomical Biomarkers for the Standardization of Asparagus racemosus Willd (Liliaceae)", 
International Journal of Research Studies in Biosciences (IJRSB), Volume 3, Issue 1, January 2015, PP 180-185

Shankar K. Mitra, Neswi S. Prakash, Ramachandran Sundaram, 2012, "Shatavarins (containing Shatavarin IV) with anticancer activity from the roots of Asparagus racemosus", Indian Journal of Pharmacology, Vol 44, Issue 6, Page No - 732-736

Shashi Alok, Sanjay Kumar Jain, AmitaVerma, Mayank Kumar, AlokMahor, Monika Sabharwal, 2013, "Plant profile, phytochemistry and pharmacology of Asparagus racemosus (Shatavari): A review", Asian Pacific Journal of Tropical Disease, Vol 3, Page
No: 242-251.

Singh, K. P., R. H. Singh, 1983, "Clinical trial on Satavari in duodenal ulcer disease", J. Res. Ay. Sid, Vol 9, Page No-155159

Venkatesan N., Thiyagarajan, V., Narayanan, S., Arul, A., Raja, S., Kumar, S.G.V., Rajarajan T., Perianayagam J.B, 2005. "Anti-diarrhoeal potential of Asparagus racemosus wild root extracts in laboratory animals", Journal of Pharmacology and Pharmaceutical Sciences, Vol 8, Page No - 39-45.

Wiboonpun N, 2004, "Identification of antioxidant compound from Asparagus racemosus", Phytotherapy Research, Vol 18, Page No - 771-73.

\section{How to cite this article:}

Pooja Shaha and Anurag Bellankimath. 2017. Pharmacological Profile of Asparagus racemosus: A Review. Int.J.Curr.Microbiol.App.Sci. 6(11): 1215-1223.

doi: https://doi.org/10.20546/ijcmas.2017.611.144 